\title{
María Cristina de Borbón-Dos Sicilias y su nieto el rey Alfonso XII
}

\author{
Palabras clave: María Cristina de Borbón-Dos Sicilias, duquesa de Riánsares - \\ Alfonso XII de Borbón - María de las Mercedes de Orleans - Isabel II.
}

María Cristina de Borbón-Dos Sicilias nunca ha gozado de buena fama y tampoco tiene buena prensa en el presente. Se le recuerda su matrimonio morganático, contraído poco tiempo después de la muerte de Fernando VII con el sargento de la guardia real Agustín Fernando Muñoz y Sánchez, que causó repercusiones negativas tanto para Isabel II como para España. En algunas publicaciones anteriores mi intención fue demostrar que a pesar de los errores cometidos por María Cristina (desde 1844 duquesa de Riánsares) en los campos político y económico, adquirió también diferentes características positivas y, por lo tanto, no merece estar marginalizada ${ }^{1}$. En particular, me refiero a su diligencia, eficiencia, inteligencia y sobre todo saber cuidar a su familia. Era un ejemplo a seguir como esposa, madre y abuela.

El objetivo del presente artículo es mostrar el tipo de relaciones cordiales que mantenía María Cristina con su nieto, desde 1874 el rey de España Alfonso XII, y a través de esta aproximación justificar la tesis que aspira a mostrar el lado humano de la duquesa de Riánsares. Todo eso, a pesar de lo que se puede leer en la literatura especializada o en Wikipedia ${ }^{2}$. Aquí, se

${ }^{1}$ B. Obtułowicz, María Amparo Muñoz y de Borbón, księżna Czartoryska, Kraków, Universitas, 2013, passim; "María Cristina de Borbón - ¿ansia del poder y del dinero o amor a su familia?", Itinerarios, Warszawa, 2013, vol. 18, pp. 141-158; "La familia Czartoryski y sus vínculos con España con La Dama del Armiño al fondo", Estudios Hispánicos, XXI, Wrocław, Wydawnictwo Uniwersytetu Wrocławskiego, 2013, pp. 145-158.

${ }^{2}$ En Wikipedia (lema: María Cristina de Borbón-Dos Sicilias, versión española) se lee: [Después de la revolución 1854 María Cristina] "Permaneció en Francia el resto de su vida y sólo volvió a España cuando su nieto Alfonso XII ocupó el trono, si bien con la limitación de no poder instalar su residencia definitiva en el país. Como curiosidad, cabe destacar que ni su hija ni su nieto tuvieron buena relación con ella, debido a que no vieron con buenos ojos su segundo matrimonio". 
enfocará el particular juego llevado por María Cristina con su nieto y con los miembros de su familia donde el papel importante le fue dedicado a las intenciones de restaurar la dinastía de los Borbones en la persona de Alfonso XII, el fortalecimiento de su reinado y dos visitas en España que efectuó para ver a su nieto. Nos interesará, sobre todo, la llegada de María Cristina a Madrid en 1878, en ocasión de la boda de Alfonso XII con su prima María de las Mercedes, y la postura de la antigua reina y la regenta hacia esa polémica relación.

La base del análisis la forman las fuentes manuscritas (cartas, telegramas, diarios, memorias) del Archivo Histórico Nacional, como también libros y artículos dedicados al tema, escasos, pero existentes.

La opinión común sobre la animadversión entre Alfonso XII y su abuela, en gran medida viene de la convicción del sucesivo empeoramiento de las relaciones entre María Cristina e Isabel II. Es verdad que su relación pasó por diferentes fases. Nunca, sin embargo, los lazos habían sido rotos de una manera definitiva. Incluso, había periodos más largos de acercamiento y comprensión mutuos. Cabe recordar que Isabel II dio luz verde para conceder títulos nobiliarios a su padrastro (duque de Riánsares) y a sus medio hermanos; que cumplió con el papel de madrina en la boda de la hija primogénita de los duques de Riánsares, María Amparo Muñoz y de Borbón con el aristócrata polaco Ladislao Czartoryski (1855), y luego decidió ser la madrina de su hijo Augusto (1858) ${ }^{3}$. Además, junto con su hijo Alfonso (en aquel entonces el príncipe de Asturias) y su hija Isabel, llegó de París a Sainte-Adresse para participar en el funeral de su padrastro $(1873)^{4}$.

Conforme con los documentos del archivo, María Cristina mantenía correspondencia epistolar y personal con todos sus nietos, también con Alfonso, a quien de alguna manera distinguía, incluso entre los miembros de su otra familia a la que le guardaba más afecto (Muñoz y de Borbón). Basta mencionar que en agosto de 1864, cuando se enteró de la llegada del príncipe de Asturias a la mansión de los Muñoz en Saint-Adresse, en vez de velar junto a María Amparo, enferma de tuberculosis, que le suplicaba la presencia en los últimos momentos de su vida, ella prefirió esperar a Alfonso. Solo apareció al lado de su hija cuatro horas antes de su fallecimiento, en el cobertizo a las afueras de París 5 .

La revolución La Gloriosa en 1868 causó el destronamiento de Isabel II forzándola a ella y a su familia a abandonar España. Desde que decidió

$<$ https://es.wikipedia.org/wiki/Mar\%C3\%ADa_Cristina_de_Borbón-Dos_Sicilias $>22$ de diciembre de 2016.

${ }^{3}$ B. Obtułowicz, María Amparo Muñoz y de Borbón..., pp. 43-44, 165.

${ }^{4}$ Biblioteca de los Príncipes Czartoryski, ms. 7195 II, A. Czartoryski a L. Czartoryski, SainteAdresse (Hotel de Phares), 16 IX 1873.

5 B. Obtułowicz, María Amparo Muñoz y de Borbón..., pp. 246-252. 
asentarse en París, la ciudad en la que desde 1854 residía su madre ${ }^{6}$, tuvo más ocasiones de ver a su nieto (Alfonso estudiaba en el colegio Stanislas en París). Cuando el joven continuó su educación en Suiza, Austria (la Real e Imperial Academia Teresiana de Viena) y en Inglaterra (Academia Militar de Sandhurst), se escribían cartas. María Cristina se interesaba por la salud de su nieto, los progresos en su educación y la situación familiar. Le animaba a forjar su carácter e intelecto, le enseñaba a ser perseverante, confiar en sí mismo y creer en lo que hacía ${ }^{7}$.

En aquel momento, lo que preocupaba a María Cristina en primer lugar era el futuro constitucional de España. Seguía con preocupación la escena política de su país colocándose del lado de los simpatizantes con la restauración de los Borbones, con su nieto como la figura principal. Por eso, expresaba desaprobación para las aspiraciones deshonestas de su tío Antonio de Orléans, duque de Montpensier, el marido de Luisa Fernanda que al principio quería ser el regente del menor Alfonso y luego pretendía el trono en Madrid. Esas intenciones compartían los políticos que estaban a favor de los Borbones: Antonio Cánovas del Castillo y Augustín Estebán Collantes, que no sin razón acusaban a Montpensier de ser cómplice en el proceso del destronamiento de Isabel II (1868), en el asesinato de Juan Prim y Prats (1870); y de tener unas ambiciones políticas desmedidas e intentar conseguir un poder absoluto. El comportamiento de su cuñado le causaba un malestar más significativo aún porque provocaba discordia entre las hijas de su primer matrimonio, es decir, entre Isabel II y Luisa Fernanda. A pesar de que esa última no apoyara la actividad política de su marido, lo que causó una separación temporal de los cónyuges, Isabel II no creía que su hermana tuviera buenas intenciones y dejó de ponerse en contacto con ella durante más de dos años. Dada la delicadeza de la situación, la madre se empeñaba en conciliar a sus hijas creyendo que "llegará el día en que todas las personas de valer le vuelvan la espada [a Alfonso]"8.

Las palabras citadas resultaron proféticas cuando en diciembre de 1874, después de los episodios del sexenio democrático (1868-1874), trágicos para España, como el gobierno transitorio encabezado por Francisco Serrano, el reinado de Amadeo I de España, la Primera República Española y en la guerra civil (la tercera guerra carlista 1872-1876); el príncipe de Asturias regresó al país y en enero de 1875 fue proclamado por las Cortes el nuevo rey de España.

Entre varias cuestiones por resolver, con las que se enfrentó el joven monarca de diecisiete años, la principal era poner el fin a la guerra civil y

${ }^{6}$ A causa del estallido de la revolución en julio de 1854, dirigida en contra de María Cristina y los moderados que apoyaba, escapó junto con toda su familia de los Muñoz y de Borbón a Francia y se asentó en el castillo de Malmaison en las cercanías de París. Tras la venta del castillo en 1861 se instaló en París.

${ }^{7}$ Archivo Histórico Nacional, Diversos, Títulos y Familias (sigue la cit. AHN, D.T. y F.), 3487, leg. 405, Notas y apuntes para el diario de la reina Maria Cristina de enero a julio de 1871; AHN, D.T. y F., 3472, leg. 349, Correspondencia de María Cristina con reales personas.

${ }^{8}$ AHN, D.T. y F., 3487, leg. 405, Notas y apuntes..., anotación del 3 de marzo de 1871. 
fortalecer la posición de Alfonso XII como el monarca legítimo. Durante los momentos difíciles que acompañaban la finalización del conflicto, el rey buscó el apoyo de la abuela que conociendo la realidad política española sabía comprender la situación en la que se encontraba su nieto 9 .

En enero de 1876, en ocasión del día del santo de Alfonso, le deseó salud y paz "para nuestra amada España"10. Todavía no presentía que dentro de poco, en marzo del mismo año, compartirían la alegría de la victoria y podría felicitarle por su valentía de haber participado personalmente en la lucha y por la aparición en el campo de batalla para anunciar el fin de la guerra. Al mismo tiempo, expresaba su profundo deseo de que su reinado fuese largo y feliz, y que lograra el respeto del pueblo. "Yo no lo conoceré ya", le escribía con dolor a su nieto, y añadía, "pero meramente el idearlo me alienta en los últimos días de mi existencia". A continuación, en la carta confesaba que ese primer gran éxito del nuevo rey ella entiende como una recompensa por el sufrimiento y la desgracia que ella misma sintió siendo regenta y luego reina madre. Al finalizar, se disculpaba por: "esta larga efusión de sentimiento, que por vehemente se abruman el alma de una anciana y cree en el inalterable profundo cariño de quien te bendice y es tu amante abuela" 11 .

Alfonso XII informaba a su abuela sobre los problemas corrientes que afectaban al país y a ella, a su vez, le servía de ayuda sugiriendo soluciones inteligentes. Le daba a entender a su nieto que para promover un poder estable y asegurar la paz interior, la garantía son un ejército fuerte y la constitución. Por eso, apreciaba mucho la educación militar de su nieto, el ardor con el que participaba en las maniobras y su preocupación por las condiciones de los militares. Le advertía que tenía que ser fiel a la constitución, cuidar la protección en el gobierno y que ojalá, gracias a todo eso, nunca tuviera que actuar de una manera arbitraria, presionado por las circunstancias ${ }^{12}$.

La siguiente cuestión aludía a una posible vuelta al país de su madre y de la abuela, conocida por los españoles como la Reina Abuela. Isabel II sí quería asentarse en su patria, pero al final decidió no hacerlo y se conformó con unas visitas ocasionales. Respecto a María Cristina, a pesar de lo que indica la bibliografía, incluida la Wikipedia ${ }^{13}$, Alfonso XII quería tenerla a su lado. El joven rey apreciaba su experiencia en el ejercicio del poder y su talento, por eso, contaba con su ayuda y sus consejos. Incluso inspiró el procedimiento para emitir un documento que permitiera la vuelta al país a su Augusta Reina Abuela $^{14}$. Sin embargo, no consiguió convencer a María Cristina que había

${ }^{9}$ AHN, D. T. y F., 3470, leg. 343, Alfonso XII a María Cristina, Madrid, 6 de enero de 1876.

${ }^{10}$ Ibidem, María Cristina a Alfonso XII, París, 16 de enero de 1876.

${ }^{11}$ Ibidem, María Cristina a Alfonso XII, París, 2 de marzo 1876.

12 Ibidem. Alfonso XII a María Cristina, Madrid, 18 de diciembre de 1876; María Cristina a Alfonso XII, París, 26 de diciembre de 1876.

13 Véase la nota núm. 2.

${ }^{14}$ AHN, D. T. y F., 3467, leg. 331, cartas anónimas, sin lugar, 8, 9, 10 y 17 de marzo de 1875 (reservado). 
decidido quedarse en Francia. En este caso, el papel principal lo representaron motivos de salud. La exregente, eminencia gris de Isabel II, la reina madre y la reina abuela, una mujer de 72 años, que enterró a sus dos maridos y cinco de los 10 hijos y una decena de los casi cuarenta nietos que tenía, se sentía mayor, débil e indispuesta. Sufría de artritis, se resfriaba con facilidad, su vista empeoraba. Además, soportar los viajes y los cambios de tiempo y clima le costaba cada vez más. Al visitar a Alfonso XII en España, en el verano 1876, le escribía a Isabel II que permanecía en París, que necesitaba calmarse, dedicar el tiempo a la contemplación y deseaba volver pronto "a mi rincón de París" 15 .

Otro motivo decisivo para no querer volver a España era la insegura situación política. A pesar de vencer a los carlistas, la escena política española presentaba varias incertidumbres. María Cristina temía que Alfonso pudiera haber sido víctima del juego de intereses de los partidos políticos que permanecían en conflicto y podía haberse convertido en la moneda de cambio en manos de los individuos corruptos. No creía en la buena voluntad humana y opinaba que sin la ayuda del absoluto en establecer el orden en el país sería imposible lograrlo. Por eso, se había apartado del mundo de la "gran política" dedicando el tiempo a rezar para que Dios le ahorrara a su nieto las decepciones y tristezas relacionadas con el poder, algo que ella conocía muy bien. "Yo huyo de que me hablen de política y deseo verme pronto en un rinconcito fuera de España, donde poder pedir tranquilamente por este País y por los objetos de mi cariño que se hallan en esta tempestad", confesaba a su hija mostrando el deseo de quedarse en Francia ${ }^{16}$.

Eso no significa que no añorase el país en el cual vivió 25 años y donde conoció el verdadero amor de su vida y donde nacieron varios de sus hijos. No obstante, el objetivo primordial que le llevó a visitar España en mayo de 1876 fue el deseo de ver a su nieto Alfonso XII. Nos podemos imaginar la alegría que sintió cuando tras varias horas de un viaje incómodo en tren, vio a su nieto en la estación en Madrid. Luego, en una carta a Isabel II le comentaba: "[le] encontré muy guapo, crecido y amable conmigo de un modo difícil de describir"17. Con el rey estaba su hermana Isabel (princesa de Asturias). Ambos nietos llevaron a su abuela al Palacio Real donde la alojaron en los apartamentos que daban a la Plazuela de Oriente. Cada día la visitaban los políticos, miembros de gobierno y gente común que quería rendirle el homenaje e intercambiar algunas palabras con ella. De vez en cuando, recorría la ciudad en un carruaje observando los cambios positivos en la capital, como el cuidado por la limpieza y la estética ${ }^{18}$. También consiguió visitar a María

15 AHN, D.T. y F., 3470, leg. 343, María Cristina a Isabel II, San Ildefonso, 7 de septiembre de 1876.

${ }^{16}$ Ibidem, María Cristina a Isabel II, Aranjuez, 9 de junio de 1876.

17 Ibidem, María Cristina a Isabel II, Aranjuez, 24 de mayo de 1876.

18 Ibidem, María Cristina a Francisco de Asís, Aranjuez, 24 de mayo de 1876. 
Manuela Kirkpatrick, la madre de Eugenia de Montijo, la antigua emperadora de la Francia de Napoleón III, en su mansión de Carabanchel ${ }^{19}$.

Después del periodo de adaptación en la capital, Alfonso XII e Isabel ayudaron a su abuela a incorporarse al tren con destino a Aranjuez donde iban a volver a verse pronto. María Cristina pasó allí unas semanas maravillosas curándose del resfriado, viéndose con antiguos conocidos suyos, paseando por los jardines del palacio bien cuidados y recordando los viejos tiempos. Luego, bajo la supervisión de sus nietos, se dirigió a la residencia de San Ildefonso de la Granja donde descansaba y reanudaba contactos con las personas con las cuales, en el pasado, había tenido intereses comunes y que habían sido sus amigos. El lugar era muy propicio para recuperar las fuerzas vitales, ya que fue allí donde en su momento se enamoraron la Reina Gobernadora, entonces de 27 años, y su guardia de corps, Agustín Fernando Muñoz ${ }^{20}$.

A Madrid llegó a mediados de septiembre para luego, al final del mes, volver a París. En sus cartas a Alfonso e Isabel les agradecía su hospitalidad, expresaba la añoranza que sentía, la nostalgia por el sol español y presentaba la esperanza de poder volver pronto ${ }^{21}$. Ese último deseo era aún más relevante porque a causa de su salud frágil y la epidemia de viruela, no consiguió llegar a Tarancón para rezar en la tumba "de mi inolvidable Fernando" [Agustín Fernando Muñoz $]^{22}$. En la respuesta, obtuvo otra invitación y las garantías del amor y apego 23 .

Los cuatro meses de estancia de la Reina Abuela en España llevaron a fortalecer los lazos entre Alfonso XII y la princesa de Asturias. María Cristina, a su vez, tenía la intención de aprovechar ese hecho para continuar sus intentos de unir a los miembros de las familias de sus hijas del primer matrimonio, es decir, Isabel II y Luisa Fernanda. En particular, quería que Alfonso XII mantuviese buen contacto con su madre y que sus relaciones con Francisco de Asís se estrechasen. No fue una tarea fácil, por no decir que era imposible. El marido de Isabel II reconoció su paternidad respecto a Alfonso XII, pero al mismo tiempo era sabido que el padre biológico del rey era el militar y aristócrata Enrique Puigmoltó y Mayans. La situación era más complicada aún por la animosidad de los esposos, el escaso interés de Francisco de criar a sus supuestos descendentes, y luego, después de 1868, la separación informal de Isabel II de su marido y sus nuevos amoríos. El joven rey, que seguramente conocía el trasfondo del matrimonio fallido de su madre, mantenía el contacto

19 Ibidem, María Cristina a Eugenia de Montijo, San Ildefonso, 15 de julio de 1876.

${ }^{20}$ Ibidem, María Cristina a Isabel II, San Ildefonso, sin fecha exacta del día de junio de 1876; María Cristina a Luisa Fernanda, duquesa de Montpensier, Aranjuez, 27 de mayo y 21 junio de 1876.

${ }^{21}$ Ibidem, María Cristina a Alfonso XII, París, 2 de octubre y 26 noviembre de 1876; María Cristina a Isabel (princesa de Asturias), París, 15 de noviembre de 1876.

${ }^{22}$ Ibidem, María Cristina a Luisa Fernanda, duquesa de Montpensier, Aranjuez, 27 de mayo y 21 de junio de 1876.

23 Ibidem, Alfonso XII a María Cristina, Madrid, 18 de diciembre de 1876; Isabel (princesa de Asturias) a María Cristina, Madrid, 11 de diciembre de 1876. 
con Francisco a través de la correspondencia epistolar, queriendo conservar las apariencias. El contacto, sin embargo, era distanciado. María Cristina quería mejorar esa relación y en sus cartas, escritas a su yerno desde Aranjuez, le animaba a que viniera a España y apoyara a su "hijo" con su experiencia en gobernar al país ${ }^{24}$. Cuando volvió a París, le informó a su nieto de que se encontraba con su buen Padre y quería hablar con él sobre el futuro de Alfonso XII y buscarle a una candidata a esposa, que sería la futura reina de España ${ }^{25}$.

Ya entonces era sabido que el rey había depositado sus sentimientos en su prima, María de las Mercedes de Orleans, hija de los duques de Montpensier. Los jóvenes se conocieron en París donde las dos familias permanecían exiliadas, dada la tensión en la política interna en España. Tras la restauración de la monarquía y la entronización de Alfonso XII en 1874, el nuevo rey dio permiso a los Montpensier y a sus hijos a regresar al país. Desde entonces el rey buscaba excusas para poder ver a su prima. Invitaba a toda la familia Montpensier a donde estaba él: Madrid, El Escorial, La Granja, o incluso él mismo les hacía visitas en Sevilla en el Palacio de San Telmo. Los amantes se veían a escondidas al atardecer, en las rejas de una ventana de la planta baja. La única enterada del romance era, al principio, Isabel II que en 1877 veraneaba en Sevilla y que mantenía silencio y discreción esperando cómo se desarrollaría la relación. En agosto el rey informó a su asesor y primer ministro, Antonio Cánovas del Castillo, de que quería casarse con María de las Mercedes. En señal de protesta, Isabel II abandonó Sevilla y se trasladó a El Escorial donde expresó su desacuerdo con la idea de tal matrimonio. La reina madre no quería que su hijo se casara con la hija de una persona que había intentado privarle de la corona. También temía que María de las Mercedes podía convertirse en una cómplice, aunque inconsciente, de su padre $\mathrm{y}$, presionada por él, influir en la actuación de su marido - lo que repercutiría en satisfacer las ambiciones personales del suegro de Alfonso XII- sin tener en cuenta el interés del estado y la dinastía de los Borbones. Al olvidar su propio caso, es decir, la presión de María Cristina y las consecuencias inoportunas de la boda con Francisco ${ }^{26}$, intentó proponer a sus candidatas, entre las cuales se encontraba la hija de la reina Victoria, la princesa Beatriz del Reino Unido. Mientras tanto, Alfonso XII, sin tomar en cuenta el descontento de su madre, anunció el compromiso y Canovás fue a El Escorial para pedir a Isabel II a que - para el bien de España — no se entrometiera en la vida privada de su hijo y que abandonara el país. La reina, disgustada, volvió a París a mediados

${ }^{24}$ Ibidem, María Cristina a Francisco de Asís, Aranjuez, 21 de junio de 1876.

${ }^{25}$ Ibidem, María Cristina a Alfonso XII, París, 2 de octubre de 1876.

${ }^{26}$ Isabel II fue obligada por su madre a casarse con su primo Francisco de Asís, príncipe de Cádiz, lo que resultó ser catastrófico tanto para la pareja como para España. 
de noviembre. El día 6 de diciembre, Alfonso XII informó las Cortes de su decisión de casarse con María de las Mercedes ${ }^{27}$.

Es significativo que durante los meses de lucha por el derecho de elegir a su esposa, el monarca no informaba a su abuela sobre sus problemas. Ella, a su vez, no parecía sufrir por la actitud discreta de su nieto, más efusivo en otras ocasiones. Estaba muy bien enterada sobre el desarrollo del asunto gracias a la correspondencia que mantenía con Francisco de Asís. Sabía que su yerno, contrariado con su hija, en ese tema compartía la opinión de su esposa, es decir, estaba en contra del matrimonio. Al mismo tiempo, opinaba que el día 28 de septiembre de 1877, cuando Alfonso cumpliría 20 años de edad, tendrían que aceptar su voluntad ${ }^{28}$. Al ser invitada por la pareja a tomar la palabra, desde el principio y con constancia estaba de parte de los nietos.

El 1 de diciembre, cuando las cosas estaban aclaradas y todo apuntaba en poder llevar al cabo el matrimonio, Alfonso XII por primera vez reveló a su abuela que la amistad con María de las Mercedes mientras tanto se había convertido en un sentimiento más profundo. Decidió casarse a pesar de correr el peligro de empeorar las relaciones con su madre, pero lo hizo porque creía que le traería suerte tanto a él como a España. Pidió a su abuela la oración y la bendición, también a que viniera a Madrid para ser la madrina en la boda: "¿Quién mejor que tú, que eres Abuela de ambos y de nosotros dos igualmente idolatrada! Este es el deseo que Mercedes me ha indicado; este es el que yo tenía desde que pensé en casarme. Así, pues, espero que harás un esfuerzo y con ese doble motivo vendrás para ese día" ${ }^{29}$. El incentivo adicional era el deseo de consultar con la abuela unas cuestiones que no podían "ser tratados en papel". Sugería que se trataba de temas del estado y de la buena imagen de María Cristina, como la antigua regenta y reina madre, a los ojos de los políticos y gente corriente ${ }^{30}$. Esa actitud confirma la confianza que le tenía el rey a su abuela y muestra que le importaba mucho que se la apreciara en España.

María Cristina justificaba su alegría por el matrimonio de Alfonso XII de la siguiente manera: en la historia de España iba a ser uno de los pocos matrimonios contraídos por amor y no por conveniencia, como mostraba su propio caso, al casarse con Fernando VII, o como fue el matrimonio de Isabel II con Francisco; María de las Mercedes iba a convertirse en la segunda reina consorte nacida en España, tras Ana de Austria (cuarta esposa de Felipe II); al contrario de lo que pensaban Isabel II y Francisco, ella encontraba en ese matrimonio la posibilidad de reconciliación entre las familias de Borbón y Montpensier. Al final, se casaban sus nietos, lo que, como ella misma acen-

27 C. Seco-Serrano, Alfonso XII, Barcelona, Editorial Ariel, 2007, pp. 121-137; A. Sagrera, La Reina Mercedes, Madrid, Compañía Literaria, 1995, pp. 261-295. de 1877.

28 AHN, D.T. y F., 3471, leg. 345, María Cristina a Francisco de Asís, Mondesir, 20 de julio

${ }^{29}$ AHN, D.T. y F., 3471, leg. 346, Alfonso XII a María Cristina, Sevilla (San Telmo), 31 de diciembre de 1877.

${ }^{30}$ Ibidem. 
tuaba, fue un acontecimiento único no solo en la historia de España. Prometía hacer todo lo posible para presenciar la ceremonia, pero no podía asegurarlo por la avanzada edad y las dolencias relacionadas con ello.

Sin embargo, advertía que si conseguía vencer las dificultades, como madrina llevaría un traje normal y no de gala, ya que a su edad de 71 años no convenía ponerse una ropa exagerada ${ }^{31}$.

El apoyo presentado hacia los nietos le costó a María Cristina la buena relación con Isabel II que durante un periodo dejó de visitar a su madre en la 79 Avenue Joséphine en París ${ }^{32}$. Francisco, por su parte, aprovechó la situación para jugar sus cartas. Contestó afirmativamente a la invitación para la boda, dirigida a él y a Isabel II. La presencia del antiguo rey consorte en una ceremonia tan distinguida haría creíble su paternidad. Además, sabía que podría encontrarse con sus antiguos conocidos, que después del 1868 se quedaron en Madrid. Isabel II, por supuesto, permaneció en Francia.

El comportamiento de la Reina Abuela en la época de preparación para la boda, luego también durante el viaje y la estancia en Madrid, atestigua la importancia que le daba al acontecimiento, a pesar de su edad hacía todo lo posible para no desilusionar a sus nietos. Ya desde principios de diciembre sus pensamientos se dirigían hacia el 23 de enero de 1878, el día previsto para la boda. Hacía las maletas y recogía los regalos tratando de acertar en las preferencias de los destinatarios. En el caso de indisposición, pensó ocupar un puesto apartado en la iglesia, mientras que al lado de los novios se presentaría otra persona indicada por ellos ${ }^{33}$. En la semana precedente a la salida ${ }^{34}$ se sentía tan mal que no abandonó la casa. Con fuerza de voluntad superó las dolencias y la tarde del 18 de enero, acompañada por su secretario particular, Antonio Rubio, y un séquito limitado, se dirigió a la Estación de Orleans y desde allí partió a Burdeos, en un tren preparado especialmente para ella. El conjunto de vagones iba a gran velocidad, se agitaba y no tenía calefacción. María Cristina aguantó heroicamente las incomodidades. Iba vestida de ropa de inverno, cubierta con una manta, trataba de dormir en su sillón convulso. Antes de alcanzar el destino, tuvo que aguantar los cambios climáticos, hacer dos transbordos (en Burdeos, donde se le unió Francisco, y en Bayona), y saludar a la gente que le daba la bienvenida en cada parada. Entre ellos se encontraban delegaciones de las ciudades, ejército, políticos, diplomáticos, miembros de burguesía. Frente a todos mantenía la amabilidad y paciencia que le eran propios. Al cruzar la frontera entre Francia y España, en Irún, apareció otro inconveniente: los guipuzcoanos

${ }^{31}$ Ibidem, María Cristina a Alfonso XII, París, 4 de diciembre de 1877; María Cristina a Luisa Fernanda de Montpensier, París,16 de diciembre de 1877.

32 Ibidem, María Cristina a Luisa Fernanda de Montpensier, París, 22 de diciembre de 1877.

33 Ibidem, María Cristina a Alfonso XII, París, 5 I 1878; Antonio María Rubio al conde de Sepúlveda, París 6 de enero de 1878.

${ }^{34}$ Las informaciones relacionadas con el viaje de María Cristina a España y su estancia en Madrid han sido recopiladas de: AHN, D.T. y F., 3472, leg. 351, [Antonio Rubio, secretario particular de María Cristina], Diario del viaje de S.M. la Reyna a Madrid en enero de 1878. 
ruidosos y agresivos, a quienes nadie sabía silenciar ya que todos hablaban en euskera. Como si fuera poco, en el compartimento dedicado a María Cristina y su séquito colocaron un brasero que aumentó la temperatura convirtiendo el interior en el trópico. El vagón, además, se inclinaba hacia un lado durante todo el trayecto.

Los inconvenientes del viaje, las interminables horas en el tren, encontraban su recompensa en las vistas de su amada tierra española bañada por el sol y en la presencia de los nietos esperándola en la Estación Norte en Madrid. El 21 de enero a las 9 horas de la mañana, tras saludarse efusivamente, Alfonso XII y la princesa de Asturias colocaron a la Reina Abuela y al rey Francisco en la carroza y los llevaron al Palacio. Allí María Cristina fue obsequiada con otros gestos de amabilidad. El rey, enterado del frágil estado de salud de su abuela, le ofreció un apartamento cómodo en la planta baja para que no tuviera que subir la escalera. Le aseguró también la comodidad y la tranquilidad al renunciar cualquier tipo de visitas a lo largo de todo el día. La tarde pudieron dedicarla a largas conversaciones, hasta las primeras horas de la noche. María Cristina se sentía "exquisitamente".

La mañana siguiente el rey se dirigió con su hermana a Aranjuez donde, en presencia de su novia y de sus padres, fue firmado el contrato matrimonial. María Cristina permaneció en Madrid por el cansancio, el resultado de un largo viaje. Durante la cena sintió escalofríos, aparecieron la fiebre y las convulsiones, por lo que tuvo que irse rápido a la cama. Al enterarse de eso, llegaron los nietos y el cuñado Francisco. El médico, marqués de San Gregorio, le prescribió un medicamento fuerte que en poco tiempo mejoró su estado. Sin embargo, María Cristina estaba demasiado débil para poder participar en la ceremonia de la boda y autorizó a su yerno Francisco y a la princesa de Asturias a que la representaran como padrinos.

Cuando en la Real Basílica de Nuestra Señora de Atocha los novios pronunciaron las palabras del juramento matrimonial, la Reina Abuela estaba en el Palacio escribiendo cartas. Escribía, entre otros, a Isabel II informándola sobre los detalles del viaje y su estancia en Madrid. La situación era muy delicada, hasta tal punto que el rey, contrariado con Isabel II pero también dedicado a la preparación de la boda, no le había enviado ningún mensaje (cartas o telegramas). María Cristina, entonces, le quería justificar y ayudar en los deberes, tanto como recuperar la confianza de su hija. Así que, los novios, al volver de la iglesia, encontraron a la abuela con la pluma en mano. Ella bendijo a los recién casados y abrazó fuertemente al nieto y a la nieta, por separado y a los dos juntos.

No tenía fuerzas para participar en la celebración de la boda, pero admitió las visitas de cualquiera que quería verla. A parte de la gente corriente, la deseaban ver los representantes de la burguesía española y políticos relacionados con diferentes opciones en el pasado. Seguía viéndose también con la pareja real, Francisco y Luisa Fernanda. Además, cada día acudía a la misa y rezaba durante varias horas por el bien de toda su numerosa familia. Es comprensible que sus 
rezos en particular fueran dedicados a Alfonso XII y María de las Mercedes porque, como pensaba acertadamente, de su suerte dependía la prosperidad de España.

La relación de María Cristina con Alfonso XII, a pesar del amor indiscutible y la empatía incuestionable, no era libre de otros intereses, como la intención de sacar provecho, no necesariamente para ella pero sí para los antiguos conocidos, especialmente para los miembros de su segunda familia de los Muñoz. Por eso, antes de abandonar Madrid, le entregó a su nieto la lista con nombres de las personas que eran de su protección. En los próximos meses le mandaría más pedidos de la misma naturaleza ${ }^{35}$. Aquí, cabe mencionar que de ese modo consiguió aceptar como miembros del Orden de Caballeros de Calatrava a Ladislao y Augusto Czartoryski y nombrarlos Grandes de España ${ }^{36}$.

La estancia de una semana de la Reina Abuela en Madrid llegó a su fin. El 28 de enero, por la tarde, llevada de mano por San Gregorio, se dirigió a los salones de sus nietos. Allí, abrazó a los dos, se despidió de ellos y subió a la carroza. El rey se aseguró de que en la estación no faltase el ejército ni la orquestra, también estaban presentes la autoridades de la capital. Ordenó también que durante el trayecto se sirviera comida caliente, preparada en un horno instalado a propósito en el vagón. Era un lujo para la época. En Hendaya los pasajeros cambiaron de tren, el ferrocarril francés arribó en la capital de Francia el 30 de enero a las 8 de la mañana. Antes, a 15 kilómetros de París, tuvo lugar una avería de la rueda que causó un retraso de dos horas.

María Cristina aguantó el viaje sin mayores problemas, salvo las dificultades con el sueño que no le dejaron dormir. Sin embargo, su estado de salud empeoraba. Perdía la vista, escribía con dificultad, hasta tener que dictar sus cartas. Cuando en abril llegó a Madrid la noticia de que se había caído y hecho daño, los nietos sentían pena de no tenerla a su lado y no poder ayudarla personalmente. Por su parte, la abuela estaba preocupada por la pérdida del bebé, sufrida por María de las Mercedes el 27 de marzo, en el primer mes de embarazo. Alfonso XII la calmaba diciendo que su mujer "está completamente restablecida y sigue la vida normal", pero a pesar de eso María Cristina le aconsejaba reposo, "no fiando en las fuerzas de la juventud"37. La salud de María de las Mercedes, tras haber perdido el niño, cambió y empeoró, pero para no inquietar a su marido le seguía acompañando en sus apariciones públicas, en su trabajo, en sus paseos, en la caza y en la corrida. A principios de junio, aparecieron dolencias gástricas, dolores de cabeza, fiebre y hemorragias

35 AHN, D.T. y F., 3472, leg. 350, María Cristina a Alfonso XII, París, 3 de abril de 1878.

36 Biblioteca de los Príncipes Czartoryski, ms. 7537 III, Herrero Martínez de Campos [ministro de guerra en España] a A. Czartoryski, Madrid, 20 de octubre de 1879; marqués de Benemeris a Sisdano (Consejero Secretario), Madrid, 15 de enero de 1880.

37 AHN, D.T. y F., 3472, leg. 350, Alfonso XII a María Cristina, Madrid, 28 de marzo de 1878; María Cristina a Alfonso XII, París, 3 de marzo de 1878. 
en los intestinos. Obviamente, esos síntomas no pudieron pasar desapercibidos para el mundo exterior.

El rey, absorbido por las cuestiones de Estado, sobre todo por la guerra con Cuba, descuidó la correspondencia con su abuela. Sin embargo, el empeoramiento repentino de la salud de su mujer causó que la abuela se convirtiera en la persona mejor enterada de la enfermedad de su nieta. También de su agonía y muerte. A partir del 17 de agosto el asustado Alfonso XII velaba día y noche al lado de la cama de la madre de su hijo perdido, el deseado sucesor de la corona española. Varias veces al día mandaba telegramas, dirigidos a la 79 Avenue Joséphine en París, informando sobre el desarrollo de la situación. En cambio, recibía respuestas donde la Reina Abuela aseguraba de sus oraciones dedicadas a su esposa, lo que confirmaba el lazo espiritual que ambos, el nieto y la abuela, compartían. Gracias a eso Alfonso XII podía ir preparándose para lo peor. La intensidad de la correspondencia cede el 26 de junio: "Ruega a Dios por mi pobre Mercedes que está en la gloria, tu afligidísimo Alfonso" 38 . Así rezaba el telegrama enviado a la abuela en los primeros momentos tras la muerte de Mercedes. Los médicos le diagnosticaron el tifus, aunque las pruebas recientes indican que la causa de la defunción fue la sepsis, adquirida tras la pérdida del niño y la consiguiente cura ${ }^{39}$.

La desolación de Alfonso XII era infinita. María Cristina, a su vez, asumió la noticia con preocupación, pero con calma. Ella sabía lo que era perder a familiares cercanos. Sentía que pronto se iría con ellos. Eso ocurrió el 22 de agosto en Sainte-Adresse, cuando estaba rodeada de los Muñoz y de Borbón ${ }^{40}$. Alfonso XII ordenó traer sus restos mortales al Real Sitio de El Escorial y depositarlos en el Panteón de los Reyes, al lado de la urna funeraria de su primer marido, Fernando VII. Fue una decisión contraria al deseo de la fallecida, ya que María Cristina quería descansar en las cercanías de Tarancón, en la Ermita Santuario de la Virgen de Riánsares, al lado del amor de su vida, Augustín Fernando Muñoz, duque de Riánsares ${ }^{41}$. Alfonso XII lo decidió así porque quería tenerla a su lado para siempre, incluso después de su muerte, ya que como rey de España tenía preparado el sitio para él en la cripta del Monasterio de El Escorial ${ }^{42}$. El destino le ahorró a María Cristina el sufrimiento causado por los romances posteriores

${ }^{38}$ AHN, D.T. y F., 3472, leg. 350, Enfermedad y fallecimiento de S.M. La Reyna Doña Mercedes de Orleans ocurrido en Madrid a 26 VI de 1878.

${ }^{39}$ A. Sagrera, op. cit, pp. 67-84.

${ }^{40}$ F. Jiménez, M. Salcedo, Augusto Czartoryski. Príncipe de Polonia-Duque de Vista Alegre. Sobrino de Isabel II de España, Madrid, Editorial CCS, 2004, p. 30.

41 F. González Doria, Las reinas de España, Madrid, Bitácora, 1989, p. 45.

42 Alfonso XII actuó como sugería la tradición que indicaba que en el Panteón de los Reyes en El Real Monasterio de El Escorial se entierra a los monarcas españoles y sus cónyuges que eran padres de los reyes españoles. María Cristina cumplía con esos requisitos: era la esposa del rey (Fernando VII) y la madre de la reina (Isabel II). 
de su nieto. Si se enteró del lado vergonzoso de la vida privada de su nieto, lo hizo estando ya al otro lado, el "lado de allá"

Los intentos de María Cristina para mantener buenas relaciones con Alfonso XII formaban parte del guión que suponía unir a toda su familia numerosa, sobre todo a las familias de sus hijos de los dos matrimonios (de Borbón y Borbón-Dos Sicilias, y de Muñoz y de Borbón). Las relaciones con Alfonso XII tomaron un carácter particular porque él iba a asegurar la continuidad del gobierno de los descendentes de Fernando VII, por lo que ella luchaba cuando desempeñaba el papel de la regenta de la menor Isabel II. La antigua Reina Regente, ya siendo la Reina Abuela, veía en su nieto el continuador de la obra que ella había promovido y desempeñado con éxito ${ }^{44}$. El joven rey, a su vez, veía en la María Cristina sobre todo a su querida abuela a la que apreciaba aún más por su valiosa experiencia, tanto en cuanto a la vida misma, como al pensar en las turbulencias que le preparaba el poder.

\section{Referencias bibliográficas}

\section{Manuscritos}

Archivo Histórico Nacional, Diversos, Títulos y Familias (AHN, D.T. y F.), 3467, leg. 331;3470, leg. $343 ; 3471$, leg. $345 ; 3471$, leg. 346; 3472, leg. 349; 3472, leg. 350; 3472, leg. 351; 3487, leg. 405.

Biblioteca de los príncipes Czartoryski, ms.: 7195 II; 7537 III.

\section{Estudios}

GONZÁLEZ DORIA F.

1989 Las reinas de España, Madrid, Bitácora.

JIMÉNEZ F., SALCEDO M.

2004 Augusto Czartoryski. Príncipe de Polonia-Duque de Vista Alegre. Sobrino de Isabel II de España, Madrid, Editorial CCS.

OBTUŁOWICZ B.

2013 María Amparo Muñoz y de Borbón, księżna Czartoryska, Kraków, Universitas.

2013 „María Cristina de Borbón - ¿ansia del poder y del dinero o amor a su familia?”, Itinerarios, vol. 18, pp. 141-158.

2013 "La familia Czartoryski y sus vínculos con España con La Dama del Armiño al fondo", Estudios Hispánicos, XXI, pp. 145-158.

SAGRERA A.

1995 La Reina Mercedes, Madrid, Compañía Literaria, S.L.

${ }^{43}$ Más sobre la doble vida de Alfonso XII vea: J.M. Zavala, Elena y el Rey. La historia del amor prohibido entre Alfonso XII y Elena Sanz, Madrid, Plaza Janés, 2014, passim.

${ }^{44}$ Recordemos que María Cristina, como Reina Regente, luchaba por mantener la corona en manos de Isabel II, a su vez, cuestionada por su tío, Don Carlos. La corona quedó en peligro una vez más tras la revolución La Gloriosa en 1868 por parte de los carlistas y el duque de Montpensier. La tarea de Alfonso XII era asegurar la continuidad de la dinastía a través de mantener el trono y dejar a un descendiente. 


\section{SECO-SERRANO C.}

2007 Alfonso XII, Barcelona, Editorial Ariel.

ZAVALA J.M.

2014 Elena y el Rey. La historia del amor prohibido entre Alfonso XII y Elena Sanz, Madrid, Plaza Janés.

\section{María Cristina de Borbón-Dos Sicilias and her grandson, King of Spain Alfonso XII}

Keywords: María Cristina de Borbón-Dos Sicilias, duquesa de Riánsares — Alfonso XII de Borbón - María de las Mercedes de Orleans - Isabel II.

\section{Abstract}

The article presents the cordial relations between Maria Cristina de Borbón-Dos Sicilias and her grandson, since 1874 King of Spain, Alfonso XII. It focuses on the truth, forgotten by historians, about a human side of Reina Abuela. The main attention is centered on a specific game played by Maria Cristina with her grandson and members of his family, in which both an intention for the Bourbon restoration in the person of Alfonso XII and a consolidation of his rule played a special role. The authors also mention two visits to her grandson in Spain, especially we are interested in Maria Cristina's arrival in Madrid in 1878, on the occasion of the wedding of Alfonso XII with his cousin Maria de las Mercedes, and the attitude of the former queen and regent to this controversial relationship. 